\title{
Incidence and Pattern of Adverse Events in Pentavalent Vaccine Recipients in Pune, India.
}

\author{
Barun Bhai Patel ${ }^{1}$, Kapil Harish Pandya, ${ }^{1}$ Bikal Shrestha, ${ }^{2}$ Atul Kotwal ${ }^{1}$ and Raj Kumar ${ }^{1}$ \\ ${ }^{1}$ Department of Community Medicine, Armed Forces Medical College, Pune, India, ${ }^{2}$ Department of \\ Community Medicine, Nepalese Army Institute of Health Sciences, Kathmandu, Nepal.
}

\section{ABSTRACT}

Introduction: Safety monitoring of vaccines used in routine programmes on immunization is important in all settings. There is a lot of debate in the country about the relevance of the pentavalent vaccine in general and the Hib component in particular, in view of reports of deaths in children following immunization. This study was conducted to evaluate the incidence and profile of AEFI in children receiving pentavalent vaccine.

Methods: A cohort study was conducted between May to Oct 2012, in a tertiary care hospital, Pune. Exposed groups received pentavalent vaccine, while the control received DPT or DPT + Hep B. Both the groups were followed up telephonically after $24 \mathrm{hr}, 48 \mathrm{hr}, 72 \mathrm{hr}$ and 7 days following vaccination. 175 children in both groups were studied. Convenient sampling was done recruiting consecutive vaccinees till the sample size was achieved. Frequency, percentage, mean difference (T test) and chi square test was used to find association

Results: $100 \%$ children were institutional delivery. In controls, $80 \%$ received DPT and Hep B, rest received only DPT. Fever was present in $76.2 \%$ among exposed and $26.7 \%$ among non-exposed. Presence of fever after 1 day following immunization was significantly associated with exposed group ( $\mathrm{P}=0.003)$. In $19 \%$ exposed group fever continued for $2^{\text {nd }}$ day. Other side effects included swelling (4.8\%) and reduced appetite (4.8\%) among exposed.

Conclusion: Pentavalent vaccine does not increase the probability of deaths among the vaccines visa-vis nor receivers. The profile of AEFI among both the groups, except fever, is similar as far as frequency and severity is concerned.

Keywords: Pentavalent, AEFI, Tertiary centre

\section{INTRODUCTION}

The Global Alliance for Vaccines and Immunisations (GAVI) and WHO recommended the use of this pentavalent vaccine in developing countries to replace the DPT vaccine. The underlying reason (as described on the GAVI website) was to be able to increase the uptake of the hepatitis $B$ and Hib vaccines in these countries by piggybacking these on a wellaccepted EPI vaccine, ie DPT. ${ }^{1,2}$

The pentavalent vaccine, consisting $\mathrm{H}$. Influenzae B (Hib) component in addition to DPT and Hep B is currently in vogue in private practice all across
India. The introduction of this vaccine in government programme is still in conceptual stages due to a lot of debate regarding the safety of Hib component in the vaccine. Several cases of adverse events following immunization (AEFI), including deaths in the vaccinees, have been reported and are attributed to the Hib component.

Before being introduced in India, the pentavalent vaccine had been used in Bhutan, Sri Lanka and Pakistan. In each of these countries, there were unexplained deaths soon after immunization. Bhutan, in fact, stopped the immunization programme after four infants died. It was later
This work is licensed under: http:// creativecommons.org/licenses/by-nc-nd/4.0/

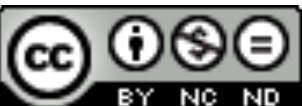

Correspondence: Barun Bhai Patel, Department of Community Medicine, Armed Forces Medical College, Pune, India. Email: barunbhaipatel@gmail.com 
persuaded to restart the programme by the WHO, which suggested that the deaths were probably due to coincidental viral meningo-encephalitis. The reintroduction of the vaccine was followed by another four deaths. Bhutan no longer uses the pentavalent vaccine. The director of public health, Dr Ugen Dophu, noted that there were no more cases of meningo-encephalitis among infants the year after the vaccine was withdrawn. ${ }^{3-6}$

Monitoring and surveillance of AEFI due to pentavalent vaccine in the UIP requires in depth analysis before it can be approved for further use. Very few prospective studies in Maharashtra have taken incidence of AEFI in pentavalent vaccine recipients as their primary research question. Safety monitoring of vaccines used in routine programmes on immunisation is important in all settings. As the rates of vaccine preventable diseases decrease, even minor common adverse events in children causes a lot of concern in the parents. Identification, detection, prevention and appropriate communication of adverse events following immunisation (AEFI) are therefore essential to preserve the integrity of immunisation programmes and protect public health.

After six months of the trial in Kerala and after five babies had died (four after the first dose of the vaccine), we considered the probability that a cluster of SIDS following immunisation had occurred by chance.

However, there is a lot of debate in the country about the relevance of the pentavalent vaccine in general and the Hib component in particular, in view of reports of deaths in children following immunization with the vaccine in these two states. ${ }^{9}$ A public interest litigation (PIL) has also been filed in the Delhi High Court against the use of the vaccine by a group of eminent pediatricians. ${ }^{7}$ This concern gains more relevance in the light of reports of deaths and severe adverse events following immunization (AEFI) due to pentavalent vaccine usage in Pakistan, Sri-Lanka and Bhutan. ${ }^{8,} 9$ This vaccine had faced a lot of scrutiny and subsequent withdrawal from the govt programme in Sri-Lanka in $2008 .{ }^{10}$

For western countries where the incidence of complicated and serious Hib infections is higher compared to that in Asian countries, the use of pentavalent vaccine in routine immunization is understandable. In fact, the introduction of the pentavalent vaccine and other Hib containing vaccines have greatly reduced the annual incidence of meningitis and severe Hib pneumonia in countries like USA and Gambia. ${ }^{11,12}$ But in Asia and the Indian sub-continent, it is believed that there is a lot of natural immunity in the children under 5 years of age owing to exposure to subclinical cases and cross-reactivity to other $\mathrm{H}$. Influenzae species. As per one community based study, the incidence of complicated Hib disease in India is as low as 0.007 percent. ${ }^{13}$ Also the efficacy of the pentavalent vaccine in comparison to separately given vaccines is low. ${ }^{14}$ Hence, it is believed that introduction of this vaccine in the national programme in the face of proven low incidence of invasive disease, absence of benefit from Hib vaccination demonstrated in the probe studies from Asia and the evidence of strain replacement in the West, appears to be a profligate exercise in futility. ${ }^{15}$

DPT is an established combination vaccine used in India on a backdrop of high disease burden and adequate country specific research. And any new vaccine finds it convenient to get combined with DPT and get introduced into the markets. But combination vaccines should be introduced only after a lot of scrutiny and deliberate understanding of the 'profit' of single visit by parents for vaccinating against multiple diseases versus the 'loss' of safety and efficacy. For example, the varicella vaccine in combination with MMR was tried, but resulted in raised instances of febrile seizures in the recipients. ${ }^{16}$ Similarly, for adults, the combination of hepatitis A with typhoid vaccine proved inefficient in comparison to both the vaccines given separately. ${ }^{17}$ Using a combination of Hep B and Hib along with DPT thus raises further questions.

However, the argument against the anticipated apprehensions of AEFI in pentavalent vaccine recipients is that the state of Goa has been using it in state funded immunization program without any difficulty of reports of severe AEFI/deaths. Same is the case with private practitioners, but authentic data in this group is not readily available. Several studies conducted on the issue in developing countries also reflect a similar opinion. ${ }^{19}$ The UNICEF suggests that that in remote areas with 
poor access to medical care, 10 per cent cases of pneumonia die. ${ }^{20}$

In the Sri Lankan episode of 2008 mentioned earlier, a detailed investigation by the WHO revealed that no serious AEFI were attributable to the vaccine as such. ${ }^{10}$ The non-fatal but serious AEFI like the hypotonic-hypo responsive episode (HHE) did occur, but it is an established side effect of Pertussis (whole cell), Hep B as well as Hib vaccines. In Sri Lanka, the survey concluded, in comparison to the previous four years, there had been an increased reporting of deaths temporarily following vaccination in 2008. The reasons for increased reporting are unclear, but the number of deaths temporarily following vaccination is not above what would be expected by chance alone based on the background neonatal and infant mortality rates. Further, the panel concluded based on its preliminary review of the "HHE-like" cases reported in Sri Lanka that although HHE was apparently unrecognized in Sri Lanka prior to the use of the liquid pentavalent vaccine, the reported cases do not show an increase above the expected reporting rate of HHE following similar vaccines.

Further, the WHO also recommends that the $\mathrm{H}$. Influenzae conjugate vaccine should be included in routine immunization programmes. ${ }^{20}$ However, some authorities believe that such a universal advocacy by the WHO for a disease which has varied epidemiological trends country-wise and without accounting for limited resources of country like India is questionable. ${ }^{15}$

Thus the present environment in the country is reeked with lack of faith in the vaccine at the national level on one side and the advocacy of making it available to the poorer classes free of cost on the other. The surveillance and reporting of AEFI has thus become a highly relevant issue in current scenario. $^{21}$

Hence this study was conducted with the aim to assess the incidence and pattern of AEFI among pentavalent vaccine recipients in Pune and also to determine the association of AEFI, if any, with socio-cultural determinants in the infants receiving vaccines.

\section{METHODS}

This study was carried out over 6 months period between May 2012 to Oct 2012. This was cohort study with children receiving pentavalent vaccine $(\mathrm{DPT}+\mathrm{Hep} \mathrm{B}+\mathrm{Hib})$ at a tertiary care hospital in Pune as exposed group and those not receiving the pentavalent vaccine but attending the clinic for some other immunization including triple (DPT) and DPT + Hep B as non-exposed group. Both the groups were followed up telephonically after $24 \mathrm{hr}$, $48 \mathrm{hr}$ and 7 days following vaccination and details of AEFI, if any, were noted as per WHO and Brighton Collaboration guidelines. ${ }^{22}$

Written and informed consent were taken from the parents prior to conducting the interviews.

SAMPLING: 175 children in each group were studied taking 95\% level of significance, $80 \%$ power, a relative risk of $1.5 \%$ in exposed group and incidence of AEFI in non-exposed group as $30 \%$. Convenient sampling was done; recruiting consecutive vaccinees till the sample size was achieved in each of the groups. The inclusion criteria included children who did not have any diagnosed medical illness (including fever, URTI or any other acute conditions), were sure to remain in Pune during the next one month after immunization and whose parents gave written and informed consent. Any child who was once interviewed was not included again during next visit to the centre. However, follow up questions were asked from such cases.

The vaccines used in this study were as provided by the hospital authorities and the authors did not have any control over the selection of the vaccines for individual subjects. All doses were delivered by trained nursing staff of the vaccination clinic and proper cold chain was maintained throughout.

Only those adverse events which fell into the category of 'certain', 'probable' or 'possible' case definitions as per WHO guidelines were included as outcomes. The parents were informed about the potential AEFI and the following were defined: fever was present if the parent was able to perceive high temperature in the child as compared to his/ her normal temperature or if temperature was $>100$ degrees $\mathrm{F}$ as measured by thermometer, redness or swelling was present if their respective size was more than $2 \mathrm{~cm}$ in diameter, bowel disturbance was defined as the child developed vomiting, diarrhoea or loss of appetite and excessive crying if the child 
60

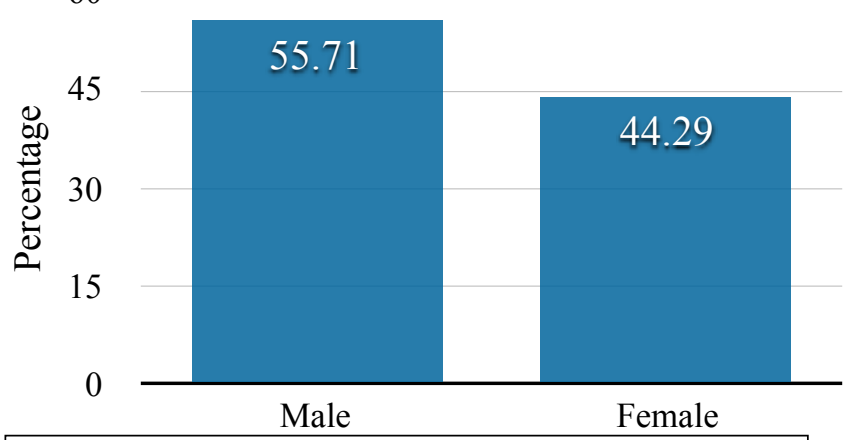

Figure 1: Gender distribution of study population

Table 1: Birth order of the children under study.

\begin{tabular}{|l|r|r|}
\hline Birth order & Frequency & Percent \\
\hline 1st & 200 & 57.1 \\
\hline 2nd & 135 & 38.6 \\
\hline 3rd & 15 & 4.3 \\
\hline Total & 350 & 100.0 \\
\hline
\end{tabular}

Table 2: Age and gender distribution in exposed and non-exposed groups.

\begin{tabular}{|l|r|r|}
\hline & Exposed & Non exposed \\
\hline Mean age in days & 87.94 & 120.43 \\
\hline $\begin{array}{l}\text { Gender (Female) } \\
\text { (count) }\end{array}$ & 85 & 70 \\
\hline Gender (Male)(count) & 90 & 105 \\
\hline
\end{tabular}

was overtly restless and crying more than his/ her normal routine.

\section{RESULTS}

A total of 350 children attending the vaccination centre were recruited after taking written, informed consent from their parents.

Out of these, 175 were in the exposed group whereas 175 were in non-exposed group. All children in both the groups were taken for analysis since there was no loss to follow-up. The gender distribution of the total vaccines is as in Fig 1.

Mean age of the participants was 104 days (95\% CI $=97$ to 111 days). The birth order, that is whether the child was first, second or third for the parents, is as shown in table 1. The age and gender distribution of the exposed and non-exposed groups is as shown in table 2.
The estimated risk (RR) of fever on $1^{\text {st }}$ day of follow up for the exposed group was 3.1 as compared to the non-exposed group. RR for excessive crying among exposed group was 1.6 times than not exposed group. Other adverse effects as reported on the $1^{\text {st }}$ day of follow up by the parents of the exposed group were pain at injection site $(2.9 \%)$, bowel disturbance $(2.9 \%)$ and swelling at the injection site $(8.6 \%)$ whereas the same were $11.4 \%, 8.6 \%$ and $2.9 \%$ respectively for the non-exposed group.

The estimated risk (RR) of fever on $2^{\text {nd }}$ day following immunization for the exposed group was 3 as compared to the non-exposed group. The same was 1.1 for excessive crying. $2.9 \%$ had swelling and $9 \%$ had bowel disturbance on the $2^{\text {nd }}$ day for the exposed group whereas the same was $0 \%$ and $3 \%$ respectively for the non-exposed group.

Comparing the exposed and the non-exposed groups for various related variables gave the following observations (Table 3).

There was a significant association between number of doses the child had received and the occurrence of fever on $1^{\text {st }}$ day follow up $(\mathrm{p}=0.042)$. Similar trend was also observed for fever on $2^{\text {nd }}$ day follow-up ( $\mathrm{p}=0.011)$. None of the child in the exposed group had any adverse effects on the $7^{\text {th }}$ day of follow up (Table 4).

For the non-exposed group, there was no association between the number of dose the child was getting and the occurrence of fever on $1^{\text {st }}$ day follow up $(\mathrm{p}=0.099)$ or on the $2^{\text {nd }}$ day $(\mathrm{p}=0.102)$. None of the child in the non-exposed group had any adverse effects on the $7^{\text {th }}$ day of follow up.

No association was found between mothers or father's education status and occurrence of adverse effects at any day of follow up in either of the groups. This study did not encounter any deaths during the 7 day follow-up period in either of the groups and at one month follow-up for the exposed group. Also, we did not observe any case of AEFI which would be classified as 'serious' or requiring hospitalization out of any of the 350 children followed up.

\section{DISCUSSION}

This study did not find any case of death or serious AEFI with pentavalent vaccine. Though the relative risk of fever on $1^{\text {st }}$ and $2^{\text {nd }}$ day of follow up was 
Table 3: Variables for the exposed group. * Income per head per month

\begin{tabular}{|c|c|c|c|c|c|c|}
\hline \multicolumn{2}{|c|}{} & \multicolumn{3}{|c|}{ Fever on 1st day follow up } & \multicolumn{3}{c|}{ Fever on 2nd day follow up } \\
\hline & Yes & No & P value & Yes & No & P value \\
\hline Age in days (mean) & 83 & 102 & 0.010 & 89 & 87 & 0.854 \\
\hline Birth weight (mean) & 2998 & 3075 & 0.215 & 2926 & 3040 & 0.128 \\
\hline Present weight (mean) & 5318 & 5896 & 0.004 & 5176 & 5546 & 0.131 \\
\hline Income (mean)* & 5448 & 6880 & 0.045 & 3750 & 6293 & 0.003 \\
\hline
\end{tabular}

Table 4: Variables for the non-exposed group. * Income per head per month

\begin{tabular}{|c|c|c|c|c|c|c|}
\hline \multicolumn{2}{|c|}{} & \multicolumn{3}{|c|}{ Fever on 1st day follow up } & \multicolumn{3}{c|}{ Fever on 2nd day follow up } \\
\hline & Yes & No & P value & Yes & No & P value \\
\hline Age in days (mean) & 133 & 116 & 0.246 & 87 & 122 & 0.183 \\
\hline Birth weight (mean) & 2974 & 2814 & 0.042 & 3500 & 2811 & 0.001 \\
\hline Present weight (mean) & 7139 & 6256 & 0.063 & 6450 & 6122 & 0.089 \\
\hline Income (mean)* & 3800 & 3914 & 0.853 & 3000 & 3942 & 0.392 \\
\hline
\end{tabular}

higher among pentavalent vaccine recipients, this was not serious enough to warrant hospitalization in any of the child. However, the incidence of fever among the exposed group was higher for the $1^{\text {st }}$ day $(71 \%)$ than that found in other studies (17.4\%) but it was similar on the $2^{\text {nd }}$ day $(17.1 \%){ }^{15}$

For the pentavalent vaccine recipients, the mean age and present weight were significantly lower on the $1^{\text {st }}$ day follow up but no such difference was found on the $2^{\text {nd }}$ day. No such differences were observed in the non-exposed group. These indicators however are not significant clinically or from a programmatic perspective since such variations are expected with any of the immunization agents. As the number of dose for the child increased, the occurrence of fever and other AEFI reduced in the exposed group but not in the non-exposed group.

Other adverse events like swelling and pain at injection site and bowel disturbances were similar in both the groups on $1^{\text {st }}$ and $2^{\text {nd }}$ day of follow up. Also, we did not observe any adverse event at the $7^{\text {th }}$ day of follow up in either of the groups.

We found that there was no association between socio-economic and education status of the parents and occurrence of AEFI in children in either of the groups.

\section{CONCLUSIONS}

This study shows that the safety profile of the pentavalent vaccine is acceptable and comparable to the vaccines already in use. Since no death (or 'serious' adverse event) was reported in this study, the attributability of the same with the vaccine could not be ascertained. Similar studies may be conducted in various cities of the country to add to the results obtained from this study. The decision on inclusion of this vaccine in national programme can be then dependant solely on the burden and incidence of $\mathrm{H}$. Influenza disease in community and not on the speculations regarding safety of the pentavalent vaccine.

\section{RERERENCES}

1. One.org. The Global Alliance for Vaccines and Immunization. Policy brief [Internet]. Undated [cited 2013 Jun 22]. Available from: http://www.one.org/c/ us/ policybrief/3260/

2. Madhavi Y. New combination vaccines: backdoor entry into India's Universal Immunization Programme? Cur Sci. 2006;90:1465-9.

3. Kuensel Online, Bhutan's daily news site [Internet]. Bhutan: Kuensel Online; c 2010-2013.Editorial The pentavalent vaccine pause; 2009 Oct 29[cited 2013 
Jun19];[about 2screens]. Available from: http:// www.kuenselonline.com/editorial-the-pentavalentvaccine-pause/\#.UanEk9jz6hp

4. Saxena KB, Banerji D, Qadeer I, Kurian NJ, Priya R, Shiva M, Puliyel J, Dabade G. "Antivaccine lobby" replies to the BMJ. BMJ. 2010 Jul 27;341:c4001. doi: 10.1136/bmj.c4001.

https://doi.org/10.1136/bmj.c4001

5. Mittal SK. Antivaccine lobby resists introduction of Hib vaccine in India. BMJ[Internet]. 2010 Jun 29[cited 2013 Jun 22];340:c3508. (Available from: http:// www.bmj.com/rapid-response/2011/11/02/suddendeaths-after-pentavalent-vaccination-vaccine-really-safe)

6. Pelden S. Bhutan News Blog [Internet]. Bhutan: [publisher unknown]. 2010 Jul 23[cited 2013 Jun 19]. (Available from: http://bhutannews.blogspot.in/2010/07/ pentavalent-killer-is-back.html)

7. "The Hindu"; Thiruvananthapuram edition. 13 Dec 2011.

8. C.M. No. 18416 of 2011 in Writ Petition (Civil) No. 13698 Of 2009 PUBLIC INTEREST LITIGATION; in the high court of Delhi at New Delhi (civil original jurisdiction.

9. "The Bhutan Daily". 28 Oct 2009.

10. http://www.int/immunization_safety/aefi/ investigation_pentavalent_Sri_Lanka/ en/index4.html

11. Watt JP, Levine OS, Santosham M. Global reduction of Hib 8. disease: What are the next steps? Proceedings of the meeting Scottsdale, Arizona. J Pediatr 2003; 143 : S163-87.

https://doi.org/10.1067/S0022-3476(03)00576-6

12. Murphy TV, Osterholm MT, Pierson LM, White KE, Breedlove JA, Seibert GB, et al. Prospective surveillance of Haemophilus influenzae type $b$ disease in Dallas County, Texas, and in Minnesota. Pediatrics 1987; 79 : 173-80.

13. Cherian T, Thomas N, Raghupathy P, Durot I, Dutta A. Safety and immunogenicity of Haemophilus influenzae type B vaccine given in combination with DTwP at 6, 10 and 14 weeks of age: author reply. Indian Pediatr 2002; 39 : 1070-71.

14. Bar-On ES, Goldberg E, Fraser A, Vidal L, Hellmann $\mathrm{S}$, Leibovici L. Combined DTP-HBV-HIB vaccine versus separately administered DTP-HBV and HIB vaccines for primary prevention of diphtheria, tetanus, pertussis, hepatitis B and Haemophilus influenzae B (HIB). Cochrane Database Systematic Rev 2009, Issue 3. Art. No.: CD005530.

https://doi.org/10.1002/14651858.CD005530.pub2

15. Zubair Lone \& Jacob M. Puliyel. Editorial Introducing pentavalent vaccine in the EPI in India: A counsel for caution. Indian J Med Res, 2010; 132:1-3.

16. Klein NP, Fireman B, Yih KW, Lewis E, Kulldorff M, Ray $P$, et al. Measles-mumps-rubella-varicella combination vaccine and the risk of febrile seizures. Pediatrics 2010; $126: 1-8$.

https://doi.org/10.1542/peds.2010-0665

17. Beeching NJ, Clarke PD, Kitchin NRE, Pirmohamed J, Veitch K, Weber F. Comparison of two combined vaccines against typhoid fever and hepatitis A in healthy adults. Vaccine 2004; $23: 29-35$.

https://doi.org/10.1016/j.vaccine.2004.05.040

18. Dodoo AN, et al. Safety monitoring of a new pentavalent vaccine in the expanded programme on immunisation in Ghana. Drug Saf. 2007;30(4):347-56. https://doi.org/10.2165/00002018-200730040-00007

19. Pneumonia the forgotten killer of children. Available at: http://www unicef.org/publications/files/ Pneumonia_The_Forgotten_Killer_of_Children.pdf, accessed on August 18, 2012.

20. World Health Organization. WHO position paper on 5 . Haemophilus influenzae type $b$ conjugate vaccines. Wkly Epidemiol Rec 2006; 81 : 445-52.

21. Buttery J, Vincente SL, Andrews R, Kempe A, Royle J. Adverse events following immunisation: desperately seeking surveillance. The Lancet Infectious Diseases, Nov 2006;6(11) $680-681$.

https://doi.org/10.1016/S1473-3099(06)70605-3

22. AEFI case definition document: The Brighton Collaboration Working Group, http://www.who.int/ immunization_safety/en/, last accessed on 15 Apr 2012. 